Daniel Chripko MD, Joan C. Bevan MD DRCOG FFARCS, David P. Archer MD FRCPC Msc, Nicole Bherer RT

\title{
Decreases in arterial oxygen saturation in paediatric outpatients during transfer to the postanaesthetic recovery room
}

\begin{abstract}
Arterial oxygen saturation was measured by pulse oximetry in two groups of paediatric outpatients breathing room air during transport from the operating room to the postanaesthetic recovery room. In Group $I(n=60)$ readiness for transfer from OR to PARR was decided clinically. In Group $I I(n=50)$ additional criteria of oxygen saturation $\left(\mathrm{SaO}_{e}\right) \geq 98$ per cent with end-tidal gas $\mathrm{N}_{2} \mathrm{O} \leq 10$ per cent and $\mathrm{CO}_{2} \leq 45 \mathrm{mmHg}$ were met. A higher incidence of desaturation $\left(\mathrm{SaO}_{2} \leq 90\right.$ per cent) occurred in Group I (27 per cent) than in Group II (eight per cent) $(P<0.05)$. More children under $2 y$ desaturated in Group I (50 per cent) than Group II (17 per cent) $(P>0.05<$ $0.10)$. Twenty-nwo patients in each group had a recent history of upper respiratary tract infections. In these patients, desaturation was more marked in those in Group I (32 per cent) than in Group II (five per cent) $(P<0.05)$. Within each group, the incidence of desaturation during transport was similar in patients with or without a recent URI.
\end{abstract}

In the immediate postoperative period, hypoxaemia can be demonstrated by pulse oximetry in one-third of healthy adults ${ }^{1}$ and children. ${ }^{2-4}$ Recently, it has been recognized that the rate of desaturation is more rapid in younger patients. During transfer from the operating room (OR) to the postanaesthetic recovery room (PARR) breathing room air, desaturation is greatest within $2 \mathrm{~min} .{ }^{3}$ However, more than half of the paediatric patients with significant arterial oxygen desaturation to 90 per cent or less do not show clinical cyanosis. ${ }^{4}$

This study audited the frequency of desaturation immediately after surgery in the population of a paediatric day surgical centre. The effect on this incidence of the use of pulse oximetry and end-tidal gas monitoring (in addition to clinical assessment) in determining readiness for transfer from the OR was then assessed. The role of recent upper respiratory tract infections in the aetiology of hypoxaemia during transport from the OR to PARR was also examined in the patients studied.

\section{Methods}

Following institutional approval, a non-randomized prospective study of 110 paediatric surgical outpatients was undertaken. Patients were ASA Physical Status I or II except for two ASA Physical Status III patients. None had haemoglobin concentrations below $100 \mathrm{~g} \cdot \mathrm{L}^{-1}$. All surgery was superficial and included dental, minor ophthalmological or urological procedures, tonsillectomies and herniorrhaphies. Any history of respiratory tract symptoms within the previous four weeks was documented. A diagnosis of URI was made if any two of the following symptoms were recorded: sore throat, rhinorrhoea, congestion, non-productive cough or fever $\left(38^{\circ} \mathrm{C}\right)$. A decision to postpone surgery because of URI was taken by the attending anaesthetist, on the basis of a current URI or severity of recent symptoms.

The choice of anaesthetic technique was at the discretion of the attending anaesthetist. Induction of anaesthesia 
with halothane inhalation or intravenous thiopentone was followed by tracheal intubation or mask ventilation. A partial rebreathing coaxial circuit, with gas flow rates to prevent rebreathing, was used for all patients. Maintenance of anaesthesia with oxygen:nitrous oxide mixtures (1:2) was supplemented with halothane or isoflurane and fentanyl intravenously. Muscle relaxation with succinylcholine or pancuronium was used as required. After completion of surgery all patients breathed 100 per cent oxygen for at least 2-3 min, or until adequate spontaneous breathing was established. Extubation was performed in the $O R$ when the patients were judged to have return of laryngeal reflexes, adequate spontaneous respiration and return of limb muscle power. Patients were then transferred to the PARR breathing room air in the lateral position with head-down tilt.

The patients were divided into two groups. Group I consisted of the first 60 consecutive patients. At the end of anaesthesia, the decision to transfer these patients from the OR to the PARR was made clinically. Group II consisted of the next 50 consecutive patients. In this group, when the anaesthetist considered that the patients were ready for transfer, they continued to breathe 100 per cent oxygen until $\mathrm{SaO}_{2} \geq 98$ per cent, end-tidal carbon dioxide $\left(\mathrm{CO}_{2}\right)$ was $\leq 45 \mathrm{mmHg}$, and end-tidal nitrous oxide $\left(\mathrm{N}_{2} \mathrm{O}\right) \leq 10$ per cent.

Arterial oxygen saturation was measured with a Nellcor $\mathrm{N}-100$ battery-powered pulse oximeter in mode 3 (Nellcor Incorporated, Hayward, CA). This mode uses a long averaging time $(10-15 \mathrm{sec})$, so the instrument is minimally affected by patient movement. ${ }^{5}$ The puise oximeter probe was attached to the patient's thumb before the end of surgery and remained in place until arrival in the PARR. Oxygen saturation was recorded at the initiation of transfer and on arrival in the PARR. The lowest reading, persisting for at least $30 \mathrm{sec}$ during transport, was noted. If the oxygen saturation was below 90 per cent, the attending anaesthetist was informed. Otherwise, the measured oxygen saturation was not disclosed.

The Puritan-Bennett 253 airway gas monitoring system (Puritan-Bennett, Wilmington, MA) was used to measure end-tidal $\mathrm{CO}_{2}$ and $\mathrm{N}_{2} \mathrm{O}$. The end of the sampling catheter was located in the elbow connector for the face mask. The dead space of the T-connector and elbow was $12 \mathrm{ml}$ and gas was sampled at $150 \mathrm{ml} \cdot \mathrm{min}^{-1}$.

The times when surgery cormmenced and ended, transfer from the OR began and the patient arrived in the PARR were noted. The anaesthetist ensured that the airway remained unobstructed and noted any coughing spells or breath-holding during transport. Statistical analysis of the results was undertaken for parametric variables. ${ }^{5,6}$ The data populations were analyzed by calculating the percentile points (2.5th, 50th, and 97.5 th percentiles) and comparing these values with the calculated mean and \pm 2 standard deviations. The data population was considered to be normally distributed if the percentile values agreed within five per cent of those calculated from the mean and standard deviation. If the discrepancy between the values was larger than five per cent, the data were summarized with the median value and the range. The two groups were compared with respect to their frequencies of significant desaturation, using the z-test ${ }^{6}$ or the Fisher Exact Test ${ }^{5}$ for comparing two proportions for statistical significance, with $P<0.05$ considered to be statistically significant in all cases.

\section{Results}

The patients in the two groups were comparable for age, with the mean (range) age in Group I of $4.8(0.3-15.4)$ yr and Group II of $5.6(0.7-15.2)$ yr. Males predominated over females with a male:female ratio of $3.6: 1$ and $1.7: 1$ in Groups I and II respectively. In both groups, otolaryngological procedures were the most common type of surgery (Table I), which is representative of the paediatric outpatient population. Tracheal intubation was performed in 36 patients in Group I and 24 in Group II. Nondepolarizing neuromuscular relaxants were used in 8 patients in Group I and none in Group II. Narcotics were given to two patients in Group I, and seven in Group II.

Data for time values were not normally distributed, so median times were used for statistical analysis. The duration of surgery and time for transport from $O R$ to PARR was similar in both groups (Table II). The median (range) time from the end of surgery to readiness for transfer to PARR was $4.5(0.8-16.5) \mathrm{min}$ in Group I and $4.3(0.5-16.0) \mathrm{min}$ in Group II.

The distribution of the lowest $\mathrm{SaO}_{2}$ values observed at any time during transport from OR to PARR is shown in Figure 1. Desaturation to $\mathrm{SaO}_{2} \leq 90$ per cent occurred in 27 per cent of Group I patients and eight per cent of Group II patients. Age and URI history of patients with significant desaturation in each group are shown in Table III.

The incidence of clinically significant desaturation in children under 2 yr was 50 per cent in Group I and 17 per cent in Group II. When compared with older children in their respective groups, any differences did not reach statistical significance $(P>0.05<0.10)$. Both ASA III patients appeared in Group I, but only one showed marked desaturation. This patient was aged $1.8 \mathrm{yr}$, an expremature with a history of respiratory distress syndrome and bronchopulmonary dysplasia, whose lowest $\mathrm{SaO}_{2}$ was 85 per cent. The other was aged $3.8 \mathrm{yr}$, born prematurely and subsequently suffering chronic respiratory problems of moderate severity. In this case, the lowest recorded $\mathrm{SaO}_{2}$ was 91 per cent. Patients with a recent 
TABLE I Distribution of types of surgery in patients studied

\begin{tabular}{lcc}
\hline Surgical procedure & $\begin{array}{l}\text { Group I } \\
(n=60)\end{array}$ & $\begin{array}{l}\text { Group II } \\
(n=50)\end{array}$ \\
\hline Otorhinolaryngological & $33(55 \%)$ & $37(74 \%)$ \\
Hemiorraphy & $10(17 \%)$ & $2(4 \%)$ \\
Ophthalmic & $6(10 \%)$ & $0(0 \%)$ \\
Dental & $1(2 \%)$ & $2(4 \%)$ \\
Urological & $2(3 \%)$ & $6(12 \%)$ \\
Other & $8(13 \%)$ & $3(6 \%)$ \\
\hline
\end{tabular}

TABLE II Duration of surgery and transport from OR to PARR

\begin{tabular}{lll}
\hline & $\begin{array}{l}\text { Group I } \\
(\min )\end{array}$ & $\begin{array}{l}\text { Group } I \\
(\min )\end{array}$ \\
\hline Duration of surgery & 29 & 24 \\
& $(4-185)$ & $(6-70)$ \\
Duration of transport & 2.2 & 2.1 \\
& $(1-6)$ & $(1-4)$ \\
\hline
\end{tabular}

Values: median (range).
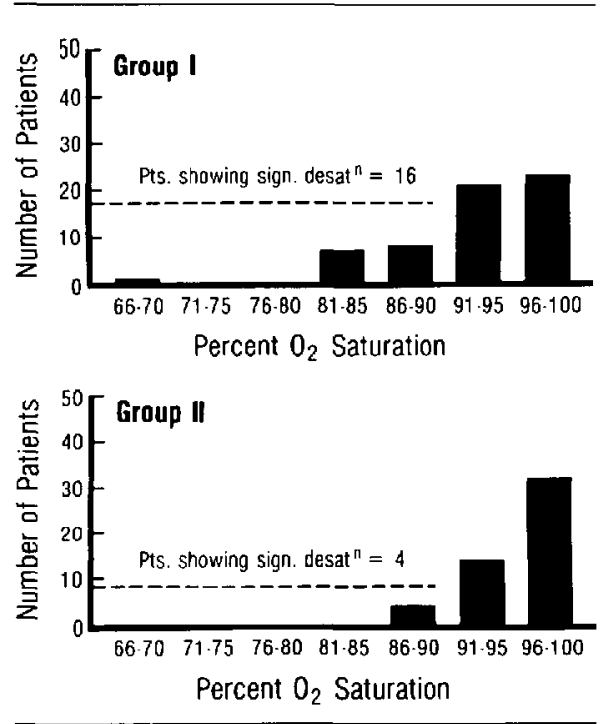

FIGURE Distribution five of the lowest $\mathrm{SaO}_{2}$ during transfer from OR to PARR.

history of URI within 4 wk also showed a higher incidence of desaturation in Group I ( 32 per cent), than in Group II (five per cent). Those patients with no recent URI history also showed a higher incidence of desaturation in Group I than in Group II. All of these differences were significant
TABLE III Correlation of age and URI in patients showing significant desaruration $\left(\mathrm{SaO}_{2} \leq 90 \%\right)$

\begin{tabular}{|c|c|c|c|c|}
\hline & $\begin{array}{l}\text { Patient } \\
\text { no. }\end{array}$ & $\begin{array}{l}\text { Lowest } \\
\mathrm{SaO}_{2}(\%)\end{array}$ & $\begin{array}{l}\text { Age } \\
(y r)\end{array}$ & URI \\
\hline \multirow[t]{16}{*}{ Group I } & 1 & 90 & 0.7 & - \\
\hline & 2 & 81 & 0.8 & - \\
\hline & 3 & 84 & 1.0 & - \\
\hline & 4 & 87 & 1.5 & ++ \\
\hline & 5 & 85 & 1.7 & ++ \\
\hline & 6 & 85 & 1.8 & ++++ \\
\hline & 7 & 88 & 3.0 & - \\
\hline & 8 & 68 & 2.8 & + \\
\hline & 9 & 85 & 3.5 & + \\
\hline & 10 & 89 & 3.2 & +++ \\
\hline & 11 & 89 & 6.0 & - \\
\hline & 12 & 89 & 6.2 & - \\
\hline & 13 & 90 & 15.4 & - \\
\hline & 14 & 85 & 7.5 & ++ \\
\hline & 15 & 90 & 7.9 & ++++ \\
\hline & 16 & 82 & 9.5 & ++++ \\
\hline \multirow[t]{4}{*}{ Group II } & 17 & 88 & 1.2 & ++ \\
\hline & 18 & 86 & 2.0 & - \\
\hline & 19 & 90 & 2.2 & - \\
\hline & 20 & 87 & 3.2 & - \\
\hline
\end{tabular}

- Healthy, no URI symptoms within 4 wk.

+ Asymptomatic, URI within 4 wk.

++ Symptoms of URI improving.

+++ Hysiory of asthma or RDS, asympromatic. ++++ History of asthma or RDS, URl improving.

(Table IV). However, there was no significant difference in the incidence of desaturation in patients with or without a recent history of URI within individual groups. Most patients breathed satisfactorily during transport and none developed laryngospasm. Coughing or breath-holding occurred in seven patients in Group I, and in ten patients in Group II. These episodes were associated with arterial desaturation in five and one patient respectively $(P<$ $0.05)$.

\section{Discussion}

In this study, clinically significant desaturation $\left(\mathrm{SaO}_{2} \leq\right.$ 90 per cent, equivalent to $\mathrm{PaO}_{2} \leq 58 \mathrm{mmHg}$ ) occurred in 27 per cent of paediatric day surgery patients treated routinely. This frequency agrees with previous reports in adults $^{1}$ and current data for children. ${ }^{2-4}$ The frequency of desaturation was reduced to 8 per cent of patients $(P<$ $0.05)$ in those in whom both pulse oximetry and end-tidal gas analysis of $\mathrm{CO}_{2}$ and $\mathrm{N}_{2} \mathrm{O}$ were used to assist in the decision to transfer from OR to PARR.

Delays in transport from the OR to PARR are obviously critical in the development of hypoxaemia. However, the times to transfer patients from the OR to PARR were the same in both groups studied, with median transfer times of $2.2 \mathrm{~min}$ in Group I and $2.1 \mathrm{~min}$ in Group II. The critical 
TABLE IV Incidence of significant desaturation $\left(\mathrm{SaO}_{2} \leq 90\right)$ in paediatric outpatients during transfer from OR to PARR

\begin{tabular}{|c|c|c|c|c|c|c|c|}
\hline & \multicolumn{3}{|l|}{ Group I } & \multicolumn{3}{|c|}{ Group II } & \multirow[b]{2}{*}{ Difference } \\
\hline & No. Pr. & $\mathrm{SaO}_{2} \leq 90 \%$ & Incidence & No. Pt. & $\mathrm{SaO}_{2} \leq 90 \%$ & Incidence & \\
\hline All patients & 60 & 16 & $27 \%$ & 50 & 4 & $8 \%$ & $P<0.05^{*}$ \\
\hline Age $<2$ yг & 12 & 6 & $50 \%$ & 12 & 2 & $17 \%$ & $P<0.10^{*}$ \\
\hline URI within 4 wk & 22 & 7 & $32 \%$ & 22 & 1 & $5 \%$ & $0.05\langle P>0.1$ N.S \\
\hline No URI history & 38 & 9 & $24 \%$ & 28 & 3 & $11 \%$ & $P<0.05^{*}$ \\
\hline
\end{tabular}

(sig *)

time at which maximum desaturation occurs in children breathing air after $3 \mathrm{~min}$ oxygen breathing is around 2 min. ${ }^{3}$ Therefore, it is possible that the short transfer times may have led to an underestimate of the differences between the two groups. Breathing 100 per cent oxygen before transfer appears to be beneficial in children. It is associated with an incidence of desaturation $\left(\mathrm{SaO}_{2}<90\right.$ per cent) of 19.6 per cent during transport, whilst breathing oxygen-enriched air (oxygen concentration 69 per cent) results in a higher incidence of 36.7 per cent. $^{7}$ Preliminary data on the efficacy of supplemental oxygen during transport from OR to PARR suggests that the incidence and severity of hypoxaemia in children can be reduced considerably but not entirely abolished. ${ }^{8}$

The relationships of age and recent URI to the occurrence of hypoxaemia were further investigated. Recent studies have suggested that younger children under 4 yr desaturate more rapidly than older children during transport, ${ }^{3}$ but the level of $\mathrm{SaO}_{2}$ is not agerelated. ${ }^{2-4}$ However, neonates and infants under $1 \mathrm{yr}$ may be more at risk for hypoxaemia. ${ }^{9}$ The degree of arterial oxygen desaturation was no different in children above or below $2 \mathrm{yr}$ ald in either group studied. Similarly, a recent history of URI could not be directly associated with hypoxaemia, although lower airway disease, prematurity and obesity are thought to predispose to its development. ${ }^{7}$

Postponement of elective surgery because of URI is common, but objective criteria for cancellation are sparse. A retrospective study of almost 4,000 children, aged $0-20 \mathrm{yr}$, found a lower complication rate intraoperatively in those presenting with URI than in asymptomatic patients with a recent history of URI. ${ }^{10} \mathrm{However}$, data on those patients who were excluded by cancellation of surgery were absent. The use of pulse oximetry is expanding so more objective information is now becoming available. Children aged $1-4 \mathrm{yr}$ with a history of URI within one week of surgery have been shown to have an increased risk of developing mild, but transient, postanaesthetic hypoxaemia $\left(\mathrm{SaO}_{2} \leq 95\right.$ per cent). ${ }^{11}$

Hypoxaemia in the early postoperative phase is multifactorial in origin. Factors producing hypoxaemia during anaesthesia, particularly a reduction in functional residual capacity, closure of small airways and ventilationperfusion disturbances, may reverse slowly. ${ }^{12}$ Additional factors during recovery include diffusion hypoxia, pain and respiratory depression. Even when children are apparently awake and recovered from anaesthesia, normoxia is not guaranteed. ${ }^{13}$

The design of this study was unblinded so there may have been differences in the conduct of anaesthesia in Group II which were not measured. Differences in clinical management, rather than the attainment of specific end-points monitored, could have been responsible for the different frequencies of arterial desaturation in the two groups. As end-tidal gas concentrations were not measured in Group I, there is no data to show whether Group IJ patients were ventilating better or eliminating nitrous oxide faster than Group I patients before transport.

Support for the use of non-invasive monitoring by pulse oximetry during anaesthesia in children is now available. It is an accurate, non-invasive method of measuring arterial oxygenation which has a rapid response. ${ }^{14}$ Early detection of hypoxaemia is more likely when the pulse oximeter is used as an adjunct to clinical assessment. ${ }^{15} \mathrm{~A}$ prospective study of 152 paediatric surgical patients has shown that hypoxaemia can be diagnosed with pulse oximetry before cyanosis or bradycardia are apparent. Hypoxic events were detected first by the pulse oximeter more frequently when the anaesthetist was unaware of its use, than when he knew of its presence. It may be concluded that the impact of sensitizing the clinicians to post-anaesthetic arterial oxygen desaturation and providing objective criteria for patient "readiness for transport" in this study reduced the incidence of arterial desaturation by almost two-thirds.

\section{References}

1 Tyler IL, Tantisira B, Winter PM, Moroyama EK. Continuous monitoring of arterial oxygen saturation with pulse oximetry during transfer to the recovery room. Anesth Analg 1985; 64; 1108-12.

2 Motoyama EK, Glazener $\mathrm{CH}$. Hypoxemia after general anesthesia in children. Anesth Analg 1986; 65: 267-72.

3 Motoyama EK, Borland L, Mutich R. The time course of 
hemoglobin desaturation during the immediate postanesthetic period in children. Anesthesiology 1987; 67: A508.

4 Pullerits J, Burrows FA, Roy WL. Arterial desaturation in healthy children during transfer to the recovery room.

Can J Anaesth 1987; 34: 470-3.

$5 \mathrm{Zar} J H$. Biostatistical Analysis. 2nd ed. Englewood Cliffs, New Jersey: Prentice-Hall, Inc., 1984, pp. 390-3.

6 Glantz SA. Primer of Biostatistics. New York, New York: McGraw-Hill Book Co., 1981, pp. 17 and 104-7.

7 Vijayakumar HR, Metriyakool F, Jewell MP. Effects of $100 \%$ oxygen and a mixture of oxygen and air on oxygen saturation in the immediate postoperative period in children. Anesth Analg 1987; 66: 181-4.

8 Patel $R$, Norden J, Hannallah RS. Oxygen administration prevents hypoxemia during postanesthetic transport in children. Anesthesiology 1988; 69: 616-8.

9 Kataria BK, Harnik EV, Mitchard R, Kim Y, Admed $S$. Postoperative arterial oxygen saturation in the pediatric population during transportation. Anesth Analg 1988; 67: 280-2.

10 Tait AR, Knight PR. Intraoperative respiratory complications in patients with upper respiratory tract infection. Can J Anaesth 1987; 34: 300-3.

11 DeSoto H, Patel RI, Soliman IE. Hannallah RS. Changes in oxygen saturation following general anesthesia in children with upper respiratory infection signs and symptoms undergoing otolaryngological procedures. Anesthesiology 1988; 68: 276-9

12 Motoyama EK, Brinkmeyer SD, Mutich RL, Walczak $S A$. Reduced FRC in anesthetized infants: effect of low PEEP. Anesthesiology 1982; 57: A418.

13 Saliman IE, Patel RI, Ehrempreis MB, Hannallah $R S$. Recovery scores do not correlate with postoperative hypoxcmia in children. Anesth Analg 1988;67:53-6.

14 Yelderman $M, N e w, W, J$. Evaluation of pulse oximetry. Anesthesiology $1983 ; 59: 349-52$.

15 Coté CJ, Goldstein EA, Coté MA, Ryan JF, Hoaglin $D C$. A single blinded study of pulse oximetry in children. Anesthesiology 1988; 68: 184-8.
Résumé

La saturation artérielle en oxygène a été mesurée avec un oxymètre digital dans deux groupes de patients pédiatriques en chirurgie d' un jour, durant le transport de la salle d'opération d la salle de réveil. Dans le Groupe I $(n=60)$, la décision de transferer le patient a été prise qu'à partir de données cliniques. Dans te Groupe $I I(n=50)$, les mesures obtenues avec l'oxymètre digital et un analyseur de gazes expirés ont servi aussi a évaluer la qualité de l'oxygènation et de la ventilation avant le transfert. Une désaturation $\leq 90$ pour cent était considerée comme significative. Un nombre plus élevé de patients dans le Groupe I (J6/60; 27 pour cent) ont subi une désaturation $\leq 90$ pour cent, comparé au Groupe ll (4/50; huit pour cent $)(P<0.05)$. Les deux groupes contenaient des patients ayant récémment souffert d'une infection des voies respiratoires supérieures. Dans ces sous-groupes, il y a eu moins de désaluration dans le Groupe 11 (1/22; 5 pour cent) que dans le Groupe I (7i22; 32 pour cent) $(P<0.05)$. L'incidence de désaturation durant le transfert n'a pas éré plus élevéchez les patients ayant eu récémment une infection des voies respiratoires supérieures. Les médianes pour l'intervalle entre la fin de la chirurgie et le début du transfert vers la salle de réveil érait respectivement de $4.5 \mathrm{~min}$ et $4.3 \mathrm{~min}$ pour les Groupes I et II. 